\title{
Game-based learning supported by audience response tools: game proposals and preliminary assessment
}

Cobos, Maximo ; Arevalillo-Herráez, Miguel ${ }^{\mathrm{a}}$; de Ves, Esther ${ }^{\mathrm{a}}$; Roger, Sandra ${ }^{\mathrm{a}}$;

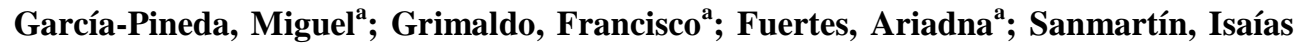
S. 'b. López-Iñesta, Emilia ${ }^{c}$; Gutiérrez-Soto, Juan ${ }^{\text {d }}$; Claver, Jose M. ' ; Castaño, Maria Asunción ${ }^{\mathrm{e}}$

${ }^{\mathrm{a}}$ Dept. d'Informàtica, Universitat de València, Spain; ${ }^{\mathrm{b}}$ Fac. de Veterinaria y Ciencias Experimentales, Universidad Católica de València, Spain; ${ }^{c}$ Fac. de Ciencias Actividad Física y Deporte, Universidad Católica de València, Spain; ${ }^{\mathrm{d}}$ Dept. de Didàctica de la Matemàtica, Universitat de València, Spain; e Dept. de Ingeniería y Ciencia de los Computadores, Universitat Jaume I, Spain.

\begin{abstract}
The so-called game-based learning strategies are based on introducing games in the classrooms to improve aspects such as student performance, concentration and effort. Currently, they provide a very useful resource to increase the motivation of university students, generating a better atmosphere among peers and between student and teacher, which in turn is generally translated into better academic results. However, the design of games that successfully achieve the desired teaching-learning objectives is not a trivial task. This work focuses on the design of games that allow the assessment of ICT-related university subjects. Specifically, four different games are proposed, all based on student participation in teams. After undertaking a preliminary evaluation of the different games, and observing the results obtained in different subjects taught by different teachers, the advantages and disadvantages of each game are discussed. This preliminary study will thus serve as an starting point for a more exhaustive study on the designed games, by including an statistical analysis considering the time variable (results in different academic courses).
\end{abstract}

Keywords: Game-based learning; undergraduate education; game design; online platforms. 


\section{Introduction}

The use of gamification in the classroom is a key element that has attracted the attention of the University community in terms of educational innovation (Kay and LeSage 2009; Melhuish and Falloon 2010). This concept attempts to incorporate techniques and dynamics of the games to improve the motivation and involvement of students in the teaching-and learning process (Eisele-Dyrli 2011). Such methods include setting challenges and using reward points, levels or rankings, in order to foster self confidence and increase the student's personal effort, involvement and collaboration with classmates. Gamification strategies may be of a very diverse nature, and they aim not only to ease the acquisition of the learning objectives of the course, but also to contribute to the personal and social development of the student. However, we shall differentiate between gamifying a learning process and using games to learn (Connolly et al. 2012; Deterding et al. 2011). Game-based learning consists of using games as a tool to support learning and to the easy acquisition and evaluation of knowledge and skills (Qian and Clark 2016). On the contrary, gamification is based on incorporating game elements (e.g. achievements, points and rankings), mechanics (e.g. challenges, rewards, feedback, competition, cooperation) and dynamics (e.g. emotions, progress) outside a game context.

One major factor that has contributed to the success of game based learning is linked to the existing relation between the factors that cause intrinsic motivation and those that characterize a good game (Connolly et al. 2012). Intrinsic motivation has a positive effect that leads the student to persist, work harder and better retain relevant information. In addition, the introduction of digital tools and the widespread use of mobile devices in the classroom have led to a significant technological change. As a result, new online tools and applications have emerged in an attempt to introduce innovative learning elements (EiseleDyrli 2011). Some of these tools not only incorporate audience response capabilities, but they also provide simple ready to use games and modes of use which encourage the use of gamification strategies (Roger et al. 2017; Bergmann and Sams 2014). Among the most popular participation management tools we find Kahoot and Socrative (Fuertes et al. 2016). These tools can be used in classrooms of various sizes and of any educational level. Although the type of user response depends on the activity design, the multiple choice questionnaire is the most popular. These tools allow the teacher to reveal the correct option after students have answered a question, and obtain real-time statistics that help assess the level of understanding of the class.

However, the use of such applications has to be adequately planned and adapted according to the learning objectives, taking into account context-dependent pedagogical considerations. In general, this is a complex task that depends of many factors, e.g. the type of content, the number of students in the group, the complexity of the game, the usage frequency or the time investment required to explain and play it. In addition, there are other 
issues that deserve careful thinking, such as question design and the weight that the activity may have on student assessment.

In this paper, we present three different game alternatives. Each of these was developed and tested in a different undergraduate degree related to ICT. They all aim to increase student motivation, but each of them has specific features that make them more suitable for a specific task e.g. continuous evaluation, the review of an specific topic, deepening in some specific content or simply breaking the rhythm of a traditional master class. Although the three games were initially thought, designed and prepared to be used in combination with Socrative or Kahoot, they are also flexible enough to be adapted to other different tools. The structure of the paper is as follows. In section 2, we describe the proposed games. Then, a preliminary assessment of these games is offered in Section 3. This is based on an analysis of their pros and cons, and also of the academic results achieved in the subjects where they were used. Finally, the conclusions of the work are presented in Section 4.

\section{Proposed games}

\subsection{Extinction}

This first game was initially designed with the aim of reviewing the contents of an entire subject, and help students establish mental links between concepts. It was applied in the context of a computer science module in a physics degree, a representative case of a foundation subject that students tend to consider outside their main interests and therefore feel less motivated. This game was considered an in-class activity and hence was played by all students in the classroom.

During the preparation phase, students are divided into teams of 5 members. Then, each person in the team receives a sheet of paper with a number written on it, and 2 tearable flaps that represent game lives. Each student in the team receives a different number, covering the full range from 1 to 5. The game consists of a typical Socrative questionnaire, which is launched after the preparation stage. Everytime a new question appears, the lecturer also announces a number in the range 1 to 5 at random. Then, the person in each team who was assigned that number has to answer the question, without the help of his/her fellows. After a reasonable time, the lecturer displays the correct result and all contestants who have failed the question have to tear one life away from his/her sheet of paper. Once a player loses the two lives, he/she becomes "extinct" (is eliminated) and the fellow with the next consecutive number becomes responsible for answering all questions assigned to that number in the future. From here on, this team member assumes a higher risk, as the chance of having to answer a question increases. As the game goes on and incorrect answers are given, group members (and some teams) become extinct. The team that preserves more lives at the end of the game is the winner, and if there is a tie, this is solved by "sudden death". 


\subsection{Who wants to be an Engineer?}

The game presented in this subsection is based on the popular game show of British origin Who wants to be a millionaire? (Wikipedia 2018), which has had a large audience and success in its TV format for many years. As the name of the game indicates, it was deployed in Engineering degrees. In particular, it has been used in Computer Engineering and Multimedia Engineering degrees during the academic years 15-16, 16-17 and the current 17-18.

Participation in the game play is proposed as a voluntary activity, and students decide whether they want to participate during the first week of class. The game is run at the end of each of the units that the subject is composed of. The objective of the the game is to review the major concepts learnt in the unit. Once the students have decided if they will participate and communicated their decision to the teacher, $n$ teams of $X$ students are created at random. Each of these teams will play the game once as contestants, at the end of one unit which is also randomly assigned to them by the teacher. The rest of the class play the role of the audience. All answers (by the team and the audience) are registered. Each game session consists of 10 multiple choice questions of an increasing difficulty level, and the rhythm of the game is controlled by the teacher. The score also increases with the difficulty of the questions, taking values from 1 to 10 that coincide with the number of question. Each time the teacher displays a new question, each student in the class (including the members of the contestant team) has to individually answer it. Once time has elapsed, the contestant team needs to agree and issue a common answer, that will determine whether the score assigned to the question is added to their scoreboard. The contestant team can fail a maximum of one question. If they fail more, the team will no longer rate as a group and only the individual scores are taken into account. To increase gamification, the contestant team can make use of the following wildcards:

- $50 \%$ wildcard: The teacher will eliminate two of the four possible options.

- Audience wildcard: Percentages of responses of the class are displayed.

The team can decide when they use these wildcards, but they can only use each once along the game. The automation of the game is achieved using the tool Socrative, that allows students to answer each question using mobile devices and the lecturer to easily analyze their responses. To give support to the mechanics of the game, each question appears twice. The student will have to answer each question the first time it is displayed on the screen. The second time, the question will only be answered by the contestant team. To encourage participation, students who played the game as contestant team are rewarded with an extra mark of up to one point, which is added to their final mark (on a 0 to 10 scale). This depends on the team's performance on the day they played as contestant (weighted one 
third) and the student's performance along the sessions they played as part of the audience (weighted two thirds).

\subsection{Teams strategy}

The main goal of this activity is to study and get a more in-depth view of all the content of the subject by means of an extensive multiple choice questionnaire. The students must answer the questionnaire using the Socrative tool within a limited amount of time. On the other hand, this activity intends to encourage the students to debate and seek consensus about the different possible answers to the proposed questions, as well as to keep the subject up to date.

Students are randomly grouped in different teams. At the end of each unit, the teams must prepare the contents of the unit so they can answer the questions in the Socrative tool. The statements of the question, without the multiple choices for the answers are provided by the teacher a few days before. Thus, the student-teams can prepare the activity in advance out of the classroom. This strategy helps the teacher to focus the activity on what he/she considers the most relevant aspects of the unit. At the moment of the activity, each team chooses a team-leader. The teacher indicates the beginning of the contest. The members of the different groups discuss the possible answers to each question. For every question, each member of a certain group has one vote in the Socrative tool (i.e. if a group is composed of 4 students, they have 4 votes for each question in the Socrative tool). If all the members of the group reach an agreement about the answer, they choose unanimously the same option. If their opinions about the correct answer differ, they can vote differently in the Socrative tool. Nevertheless, an strategy about the different individual answers can be followed so that the group can maximize the options to increase the final score of the test.

The score of the team is the sum of the correct answers of all its members. At the end of the activity, the score of the students, individually, is the sum of all the correct answers of all the members of his/her team. That is, the score of the student matches the score of his/her team. At the end of the activity, some extra points are assigned to each groups depending on the position in the score ranking. The groups better ranked receive more additional points than the worst. By introducing this gamification strategy, the members of different groups are discouraged to share information about the answers.

\section{Preliminary assessment: advantages and disadvantages}

This section discusses the advantages (+) and disadvantages (-) that have been identified throughout the approach and implementation of the various games explained above. Note that all are related to the subjective opinions received by the teachers running the games, so special care must be taken when interpreting them. Future work will analyze in more depth the following aspects with the data collected at the end of the course. 
For each game, we will specify the considered subjects and degrees where it has been implemented, the degree year and the number of students involved.

\subsection{Extinction}

The realization of this game in the subject "Computer science" of the first course of the Degree in Physics has been very useful to motivate the students' learning. The total number of students per class was around 60. As a result of the implementation of the game during two academic years (16-17 and 17-18), the following aspects can be highlighted:

+ The degree of students' satisfaction and their motivation towards the contents of the subject seems to be increased with respect to their initial perception.

+ The dynamics of the game are easy to explain and have been shown to be suitable for crowded groups (between 40 and 60 students).

- There is a decrease in students' participation due to early disqualifications, so it is advised to intercalate medium-low complexity questions in order to delay an early extinction.

- It is difficult to keep students' attention after the correct answer has been revealed by the teacher, since the discussion of answer results among the students causes distraction.

\subsection{Who wants to be an Engineer?}

This contest-inspired game was held in a first year course of the Degree in Computer Engineering called "Computer fundamentals"; and in the course "Sound systems and music technology", which is delivered to students in the fourth year of the Multimedia Engineering degree. The number of participants were 60 and 15, respectively. Major aspects to mention are:

+ Team and individual assessment are combined.

+ It was a motivating activity for students in the first year, who explicitly asked to increase the sessions dedicated to contests.

- The applicability of the approach decreases with the size of the group, as deployment time becomes larger.

- Less motivation was observed in the case of more mature students in the fourth year, some of whom reported boredom in the last sessions.

- The teacher needs to invest a large amount of time to prepare the required infrastructure and design the questions which are used through the game. 


\subsection{Teams strategy}

This activity was designed for the subjects "Cellular Biology" and "Virology" of the first and third years, respectively, taught in the Biotechnology Degree of the Catholic University of Valencia in the 16-17 and 17-18 academic years. Some of the positive and negative points of the activity worth highlighting are the following:

+ It develops a sense of responsibility in the student towards his group, as he/she must contribute to the group with meaningful information during the response phase.

+ It encourages students to share and understand better the learnt contents while preparing the set of questions.

+ A suitably chosen set of questions allows to direct students towards the essential contents of the subject.

+ Providing the statements of the questions beforehand prevents the students from considering this type of activities like an excessive work overload during the course.

- The success of the activity depends on an extensive enough set of questions to cover an entire topic, which involves an often great workload for the teacher.

- As the course progresses, the students may stop preparing the topics due to the workload of other subjects. If this may happen, the activity fails to meet the pursued objective.

- The time spent on this type of sessions often makes teachers leave aside other types of activities which may be of higher priority (solving problems, explaining all the contents of the subject, etc.). So its suitability as a learning activity depends a lot on the type of subject.

\section{Conclusion}

In this paper, we have described three different game proposals to help learning in the classroom. Although the three games have some similarities (e.g., all of them are based on participation by teams), each of them has different characteristics in terms of the type of participation of students, including the interaction among each other and with the teacher. The games have been initially tested in different degrees of three Spanish universities, obtaining a set of considerations to be taken into account before a wide application of them. The three proposals have several advantages and disadvantages that are directly related to the complexity of the rules, the permanence of the teams in the game, the type and number of questions, and their duration over time.

As a general conclusion, we can say that, in its implementation, an improvement in the motivation of the students to learn the contents has been observed. However, this motivation seems to decrease when the game is repeated in too many sessions, especially on students of last courses. The most important drawback, which is common to all games, 
is the time to be invested by teachers to develop an extensive battery of questions as well as the time taken to carry out the game itself. This aspect is especially critical in the case of the game Who wants to be an Engineer?, since it also requires that the questions have an increasing complexity in order to maintain the philosophy of the original contest. Overall, we can conclude that the initial results of the use of the proposed games have been qualitatively positive, and the future analysis of the results obtained will help us to propose improvements in this kind of activities based on data evidence.

\section{References}

Bergmann J. and Sams, A. (2014). Flipped Learning: Gateway to Student Engagement. International Society for Technology in Education (ISTE).

Connolly, T. M., Boyle, E. A., MacArthur, E., Hainey, T. and Boyle, J. M. (2012). A systematic literature review of empirical evidence on computer games and serious games. Computers and Education, 59(2), 661-686.

Deterding, S., Dixon, D., Khaled, R. and Nacke, L. (2011). From game design elements to gamefulness: defining gamification. In Proceedings of the 15th International Academic MindTrek Conference, 9-15.

Eisele-Dyrli, K. (2011). Mobile goes mainstream. District Administration, 47(2), 46-55.

Frías, M.V., Arce, C. and Flores-Morales, P. (2016). Uso de la plataforma socrative.com para alumnos de química general. Educación Química, 27(1), 59 -66.

Fuertes, A., García, M., Castaño, M. A., López, E., Zacares, M., Cobos, M., Ferris, R. and Grimaldo, F. (2016). Uso de herramientas de respuesta de audiencia en la docencia presencial universitaria: un primer contacto. In XXII Jornadas sobre la Enseñanza Universitaria de la Informática (JENUI 2016), Almería, Spain, 257-265.

Kay, R. and LeSage, A. (2009). A strategic assessment of audience response systems used in higher education. Australasian Journal of Educational Technology, 25(2), 235-249.

Melhuish, K. and Falloon, G. (2010). Looking to the future: M-learning with the ipad computers in New Zealand schools. Learning, Leading, Technology, 22(3), 1 - 16.

Qian, M. and Clark, K. R. (2016). Game-based learning and 21st century skills: A review of recent research. Computers in Human Behavior, 63, 50 - 58.

Roger, S., Cobos, M., Arevalillo-Herráez, M., and Garcia-Pineda, M. (2017) Combinación de cuestionarios simples y gamificados utilizando gestores de participación en el aula: experiencia y percepción del alumnado. In Congreso IN-RED 2017, Universitat Politècnica de València, Valencia, Spain, 1-12.

Wikipedia. (2018). Who wants to be a millionaire? Available online at: https://en.wikipedia.org/wiki/Who_Wants_to_Be_a_Millionaire\%3F. 